\title{
Yield of Saffron (Crocus sativus) Under Different Corm Densities
}

\author{
Abdel Kader El Hajj ${ }^{1}$, Sally Moustafa ${ }^{2}$, Soha Oleik ${ }^{1}$, Vera Telj $^{1}$, Nour Taha ${ }^{1}$, Hanaa Chehabeldine ${ }^{3}$ \\ \& Tamim El Tachach \\ ${ }^{1}$ Lebanese Agricultural Research Institute, Lebaa, Jizzin, Lebanon \\ ${ }^{2}$ Faculty of Agricultural Science, The Lebanese University, Dekwane, Beirut, Lebanon \\ ${ }^{3}$ Lebanese Agricultural Research Institute, Fanar, Jdeideh, El Metn, Lebanon \\ Correspondence: Abdel Kader El Hajj, Lebaa Station, Lebanese Agricultural Research Institute, P.O. Box 287, \\ Zahle, Tal Amara, Bekaa, Lebanon. Tel: 961-7230-014. E-mail: ak.hajj@lari.gov.lb
}

Received: February 27, $2019 \quad$ Accepted: April 9, $2019 \quad$ Online Published: June 15, 2019

doi:10.5539/jas.v11n8p183 URL: https://doi.org/10.5539/jas.v11n8p183

\begin{abstract}
Due to its valuable properties, Saffron is considered one of the most expensive spices. Saffron was introduced to Lebanon in 2000 and promoted as alternative crop to Canabis Sativa. There has been little research for saffron on a variety of subjects, in particular on cultural practices. The aim of this study is to investigate the impact of corm density on Saffron yield attributes. The study included three corm densities that were organized in randomized complete block design with three replicates; Low(LD)- 25 corms m${ }^{-2}, 20 \times 20 \mathrm{~cm}$ spacing; Moderate (MD)-44 corms $\mathrm{m}^{-2}, 15 \times 15 \mathrm{~cm}$ spacing; High (HD)-100 corms m${ }^{-2}, 10 \times 10 \mathrm{~cm}$ spacing. The study was conducted at the Lebanese agricultural research institute (LARI) in Lebaa station for four consecutive years. Results showed a steadily significant high yield of flowers $\mathrm{m}^{-2}$ at high density compared to low density for four years .In contrast, the number of flowers (NF)/100 corm clusters (CC) was significantly increased at low density in last two years compared to high density. Treatments showed no significant effect of the main compounds of air-dried stigmas (Crocin, Picrocrocin and Safranal). Fresh (FWSS) and dry (DWSS) weight of single stigma was affected by year showing a significant change from year to year. These results revealed that success of long-term cultivation can be achieved by planting saffron corm at moderate and low densities.
\end{abstract}

Keywords: corm density, Crocin, LARI, moderate density, Saffron, Stigma

\section{Introduction}

Saffron is valued as the most expensive spice by its diverse uses and benefits (food, medicinal uses, cosmetic, perfumes and production of textile dyes) (Kumar et al., 2009; Mousavi \& Bathaie, 2011). It belongs to Irridaceae family and is geographically distributed in Mediterranean climates, East Asia and Irano-Touranian regions (Kafi, Koocheki, \& Rashed, 2006; Kumar et al., 2009). Although, Saffron tolerates various soil types, it grows well on clayey calcareous soils (Kumar et al., 2009). Stigmas and corms represent the most valuable parts of saffron. Crocin, picrocrocin and safranal are responsible for color, bitterness and aroma respectively. Saffron is mainly cultivated in a small number of countries (Iran, India, Spain, Italy, Greece, Morocco and New Zealand) where it plays an important economic role especially in marginalized areas. Saffron yield $\left(\mathrm{kg} \mathrm{ha}^{-1}\right)$ varies greatly among these countries. In Khorassan, under different farm management practices the mean yield of saffron ranged 4-6 $\mathrm{kg} \mathrm{ha}^{-1}$ (Jami-alahmadi, Behdaniand, \& Akbarpouret, 2010). The yield of 8.4 and $6.5 \mathrm{~kg} \mathrm{ha}^{-1}$ was obtained in Italy and Spain respectively (Golmohammadi, 2014), while in Kashmir ranged from 1.57 to $3.74 \mathrm{~kg} \mathrm{ha}^{-1}$ for several years (Husaini et al., 2010). In New Zealand, a yield of $24 \mathrm{~kg} \mathrm{ha}^{-1}$ was produced (Gresta, Lombardo, Siracusa, \& Ruberto, 2008).

Apart from other factors, Saffron yield substantially depends on corm density and size. Corm density is an agricultural procedure that should have a special care due to its considerable role in increasing saffron yield and reducing establishment cost in case of selecting low corm density. Mollafilabi, Koocheki, Moeinerad, and Kooshki (2013) reported that the highest yield was achieved under the high density of $150 \mathrm{corms} \mathrm{m}^{-2}$. High density was also reported by (Andabjadid, Eslam, Bakhtavari, \& Mohammadi, 2015) to have a positive effect on the saffron yield. Other authors suggested that a density of $50 \mathrm{corms} \mathrm{\textrm {m } ^ { - 2 }}$ is suitable for obtaining maximum yield (McGimpsy, Douglas, \& Wallace, 1997). These conflicting results could be due to different environments and 
farm management under which these studies were conducted. Other agricultural practices such as fertilization, weed management and control of rodent animals are essential for obtaining high saffron yield.

In Lebanon Saffron was considered and promoted in the late 1980s and 1990s as alternative crop to Canabis Sativa (El Takach et al., 2017). Several attempts to introduce this crop have been made and trials have taken place in different localities. However, Saffron cultivation in Lebanon and despite appropriate weather and geographical conditions, did not reach the desired target (level of producing countries). Until recently, there were little researches on Saffron in Lebanon. Several research programs aimed at developing saffron cultivation in Lebanon including this study were initiated by the Lebanese Agricultural Research Institute (LARI). Our goal is to determine the optimum corm density for saffron cultivation in clayey calcareous soils under field conditions.

\section{Material and Methods}

The study was carried out from 2013 to 2016 at the Lebanese Agricultural research Institute-Lebaa station $\left(33^{\circ} 32.681^{\prime}\right.$ North, $35^{\circ} 27.088^{\prime}$ East, $354 \mathrm{~m}$ a.s.l., $650 \mathrm{~mm}$ rainfall). The corms with relatively moderate homogeneity were planted on August .The study was organized in randomized complete block design with three replicates. Corms were planted at three densities (high density (HD) $100 \mathrm{corms} \mathrm{m}^{-2}$, Moderate (MD) 100 corms $2.25 \mathrm{~m}^{-2}$, low (LD) 100 corms $4 \mathrm{~m}^{-2}$ ). 100 corms were allocated to each experimental unit and organized in randomized block design with three replicates. Flowers were collected early in the morning. The separated stigmas (red part of stigmas) were dried under ambient lab temperature. Number of flowers (NF) per 100 corm clusters CC (each cluster was grown from one mother corm) and per $\mathrm{m}^{2}$ were recorded. Fresh (FWS) and dry (DWS) weight of stigmas $/ 100$ corm clusters (CC) and $\mathrm{m}^{2}$, fresh and dry weight of single stigma were weighted on a prices digital balance up to $0.000 \mathrm{~g}$ accuracy. The components of air-dried stigmas (Crocin, Picrocrocin and Safranal) were determined according to ISO 3632-2:2010 test method by using UV-vis spectrophotometer. The results for these three compounds were obtained by direct reading of the specific absorbance at three wavelengths (257 nm-picrocrocin, $330 \mathrm{~nm}$-Safranal, $440 \mathrm{~nm}$ crocin). Repeated measure of anova using mixed procedures was performed in SAS 9.2 for Windows (SAS Institute Inc., Cary, NC, USA) to evaluate the effect of treatments on yield parameters. Tukey's multiple comparisons test of significance at $p=0.05$ was used to evaluate differences between these groupings at individual year.

\section{Results and Discussion}

The collected data over 4 years of experiment were analyzed by mixed procedures for repeated measures.

Figure 1 depicts the yield pattern of the number of flowers (NF)/100 corm clusters (CC) over four years as affected by corm density. The results showed that the NF/100 CC was significantly affected by treatments (planting density) $F(2,4)=6.65, p=0.0535$, year $F(3,6)=65.43, p<0.0001$ and their interaction $F(6,11)=$ $7.82, p=0.0019$. This indicates that the three planting densities were affecting NF differently over years. No significant effect of corm density was observed during the first year (2013). High density (HD) in 2014, showed a significant difference compared to low density (LD). In the following two years (2015 and 2016), low density yielded a significantly high NF/100 CC compared to high density (Figure 1). This pattern of growth is referred to the competition for nutrient among corms planted at high density. Competition for nutrient was reported to cause stress for plants (Craine \& Dybzinsky, 2013). A research study regarding the effect of corm density on saffron yield was conducted by Yua and Nihmeah (2004) in Bekaa valley (Lebanon). Although the geographical and environmental conditions of the site of this study differ, they reported similar results regarding positive effect of low density. Our results agree with the findings obtained by Singh and Ahuja (2012); Singh and Shamra (2017); Alonso and Diaz-Marta (2006). Seyyedi, Ebrahimian, and Rezaei-Chiyaneh (2018) reported that high densities have a negative effect on daughter corms, through increasing competition for nutrients. 


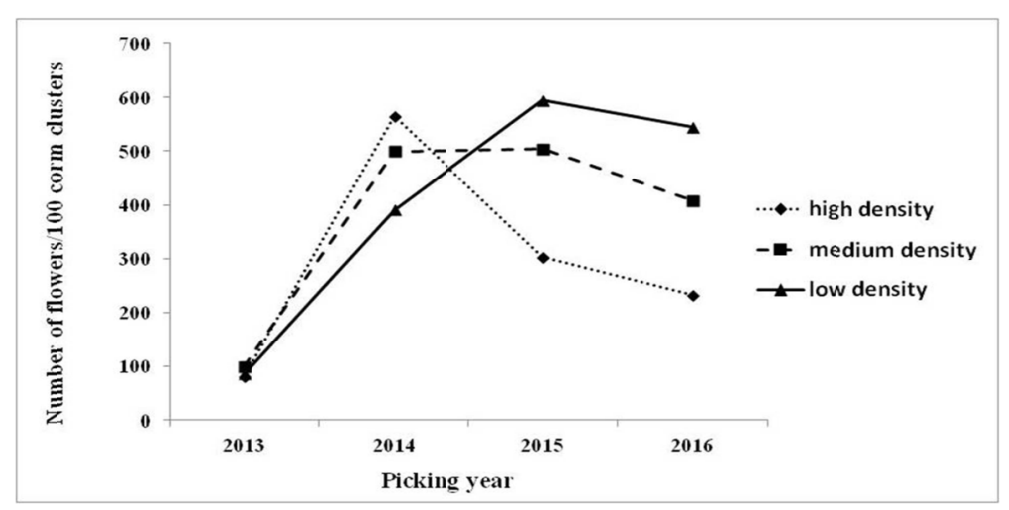

Figure 1. Number of flowers/100 corm clusters (CC) as affected by corm density through four years of cultivation at the Lebanese Agricultural Research Institute (LARI) in Lebaa region

In contrast, corms planted at high density produced a steadily higher NF per unit area (UA) compared to low and moderate densities (Figure 2). This was indicated by mixed procedures that revealed significant effect of treatments $(F(2,4)=115.98, p=.0003)$, year $(F(3,6)=90.32, p<.0001)$ and their interaction $(F(6,11)=26.67$, $p \leq .0001$ on the $\mathrm{NF} / \mathrm{m}^{2}$. Similar results were reported by De Juan et al. (2009).

These contrasting results regarding yield per unit area and per mother corm as affected by corm density are in fact reflecting the real picture. Planting high number of corms is expected to produce high number of flowers when it is calculated per unit area. However when it is calculated per biological unit such as mother corm, the yield is reduced at high density due to high competition for nutrient source.

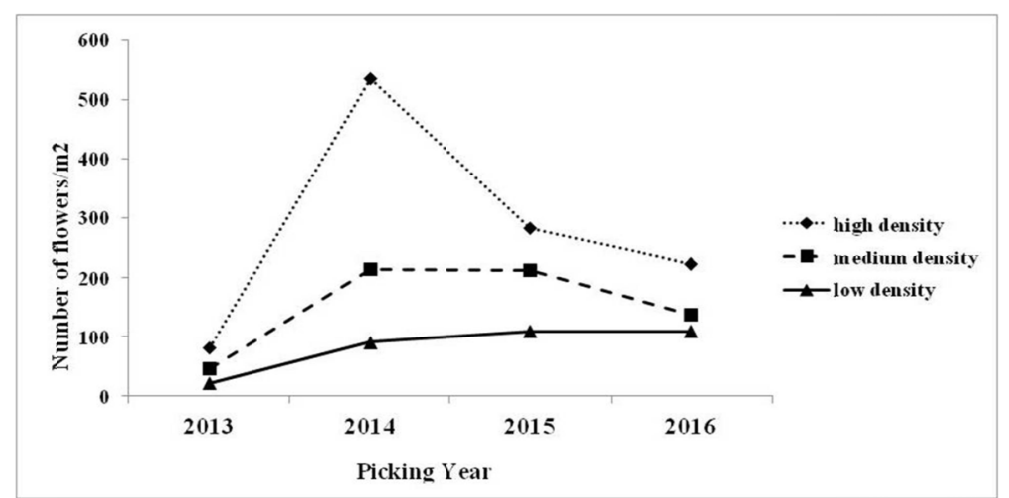

Figure 2. Number of flowers $/ \mathrm{m}^{2}$ as affected by corm density through four years of cultivation at the Lebanese Agricultural Research Institute (LARI) in Lebaa region

The same pattern of significance was observed for fresh (FWS) and dry (DWS) weight of stigmas $\mathrm{m}^{-2}$. The mixed procedures for repeated analysis revealed a significant effect of year, treatments and their interaction (Table 1). Moreover, the yield of dried stigmas $\mathrm{m}^{-2}$ at low density did not change remarkably from 2014 to 2016 (Table1), whereas high and moderate densities showed an extreme decrease from 3.03 and $1.35 \mathrm{~g} \mathrm{~m}^{-2}$ to 0.9 and $0.63 \mathrm{~g} \mathrm{~m}^{-2}$ respectively (Table 1). This drop in dry weight of stigmas was most likely due to the lack of fertilization program during the trial period. Despite this decrease, it remains within acceptable limits. Nevertheless, Jami-alahmadi, Behdani, Akbarpouret (2014) reported in their work that saffron farm age plays an important effect on yield and the highest yield was observed in farms that practiced better farm managements including manuring practices.

Regarding fresh and dry weight of stigmas/100 CC, results displayed a significant difference between treatments. In 2014, high density yielded a significant dry and fresh weight of stigmas/100 CC compared to low density. In 2015, low density demonstrated superiority over high density. No significant differences between treatments were observed in last year (Table1). 
The mixed test for repeated analysis showed no significant effect of treatment and year-treatment interaction on fresh and dry weight of single stigma. The values of both parameters were changing over time (year) as shown by the mixed test (Table 1).

The main components determining Saffron quality were analyzed by ISO method. The analysis of variance showed no significant effect of plant density on Crocin, Picrocrocin and Safranal contents (Table 2). These results agree with findings obtained by Koocheki and Seyyedi (2016). According to ISO specification and qualification, the values of three components fell within the first category.

Table 1. Mean comparisons of Saffron yield attributes (Fresh and dry weight of single stigma-FWSS, DWSS; Fresh and weight of stigma-FWS, DWS) in different corm densities over three year in Lebaa station

\begin{tabular}{|c|c|c|c|c|c|c|c|}
\hline Harvest year & Corm Density & FWSS (g) & DWSS (g) & $\begin{array}{l}\text { FWS } \\
\text { (g/100 corm clusters) }\end{array}$ & $\begin{array}{l}\text { DWS } \\
\text { (g/100 corm clusters) }\end{array}$ & FWS $\left(\mathrm{g} / \mathrm{m}^{2}\right)$ & DWS $\left(\mathrm{g} / \mathrm{m}^{2}\right)$ \\
\hline \multirow[t]{5}{*}{2014} & High & 0.036 & 0.0057 & $20.1 \mathrm{a}$ & $3.20 \mathrm{a}$ & $19.00 \mathrm{a}$ & $3.03 \mathrm{a}$ \\
\hline & Medium & 0.038 & 0.0061 & $17.0 \mathrm{ab}$ & $2.89 \mathrm{ab}$ & $8.39 b$ & $1.35 \mathrm{~b}$ \\
\hline & Low & 0.036 & 0.0059 & $14.2 \mathrm{~b}$ & $2.28 b$ & $3.31 \mathrm{c}$ & $0.53 \mathrm{c}$ \\
\hline & $P$ & .53 & .18 & .02 & .03 & $<.0001$ & $<.0001$ \\
\hline & $\eta^{2}$ & .19 & .43 & .75 & .75 & .97 & .96 \\
\hline \multirow[t]{5}{*}{2015} & High & 0.029 & 0.0053 & $8.7 \mathrm{~b}$ & $1.59 \mathrm{~b}$ & $8.18 \mathrm{a}$ & $1.49 \mathrm{a}$ \\
\hline & Medium & 0.021 & 0.0051 & $15.1 \mathrm{a}$ & $2.64 \mathrm{ab}$ & $6.41 \mathrm{ab}$ & $1.12 \mathrm{ab}$ \\
\hline & Low & 0.029 & 0.0052 & $17.2 \mathrm{a}$ & $3.10 \mathrm{a}$ & $4.00 \mathrm{~b}$ & $0.72 b$ \\
\hline & $P$ & .50 & .76 & .02 & .02 & .01 & .01 \\
\hline & $\eta^{2}$ & .20 & .09 & .75 & .72 & .77 & .77 \\
\hline \multirow[t]{5}{*}{2016} & High & 0.021 & 0.0039 & 5 & 0.95 & 4.77 & 0.90 \\
\hline & Medium & 0.022 & 0.0044 & 7.4 & 1.31 & 4.06 & 0.79 \\
\hline & Low & 0.021 & 0.0041 & 9.7 & 1.50 & 2.80 & $0 . .55$ \\
\hline & $P$ & .67 & .47 & .08 & .23 & .13 & .19 \\
\hline & $\eta^{2}$ & .12 & .22 & .70 & .26 & .63 & .56 \\
\hline \multicolumn{8}{|c|}{ Repeated analysis of variance } \\
\hline Trt & $\boldsymbol{P}$ & .76 & .28 & .22 & .15 & .001 & .001 \\
\hline Year & $P$ & .01 & .003 & .005 & .009 & 0.002 & .003 \\
\hline Trt*year & $\boldsymbol{P}$ & .45 & .52 & .03 & .002 & .0003 & .001 \\
\hline
\end{tabular}

Table 2. Moisture content and qualitative parameters of air dried saffron stigmas as affected by corm density

\begin{tabular}{lllll}
\hline Corm Density & Moisture content (\%) & Crocin $\left(A_{1 \mathrm{~cm}}{ }^{1 \%} 440 \mathrm{~nm}\right)$ & Picrocrocin $\left(A_{1 \mathrm{~cm}}{ }^{1 \%} 257 \mathrm{~nm}\right)$ & Safranal $\left(A_{1 \mathrm{~cm}}{ }^{1 \%} 330 \mathrm{~nm}\right)$ \\
\hline High & 9.3 & 266.6 & 93.0 & 40.6 \\
Medium & 9.4 & 267.4 & 99.1 & 42.6 \\
Low & 12.3 & 260.5 & 91.1 & 46.8 \\
\hline Anova & & & & \\
Df & $\mathbf{2 , 6}$ & $\mathbf{2 , 6}$ & $\mathbf{2 , 6}$ & $\mathbf{2 , 6}$ \\
$\boldsymbol{P}$ & .45 & .96 & .84 & .92 \\
$\boldsymbol{\eta}^{2}$ & .23 & .01 & .06 & $\mathbf{0 . 0 3}$ \\
\hline
\end{tabular}

\section{Conclusion}

According to our results, corm density affected the main yield parameters differently with respect to unit area and 100 corm clusters. High density decreased the potential of mother corm to produce high yield after several years of cultivation in contrast to low density which showed a promising result in increasing the number of flowers and other yield parameters. Therefore, planting $20 \mathrm{corms} \mathrm{m}^{-2}$ instead of 100 will reduce corm cost and maintain an acceptable yield over several years.

\section{Reference}

Alonso Diaz-Marta, G. L., Arghittu, A., Astrka, K., Petza, T., Cilloco, M. T., \& Corona, G. (2006). Saffron in Europe Problems and Strategies for improving the quality and strengthen competitiveness. Annex White Book.

Andabjadid, S. S., Eslam, B. P., Bakhtavari, A. R. S., \& Mohammadi, H. (2015). Effects of corm size and plant density on Saffron (Crocus sativus L.) yield and its components. International Journal of Agronomy and Agricultural Research, 6(3), 20-26. 
Craine, J. M., \& Dybzinski, R. (2013). Mechanisms of plant competition for nutrients, water and light. Functional Ecology, 27, 833-840. https://doi.org/10.1111/1365-2435.12081

De Juan, J. A., Córcoles, H. L., Munoz, R. M., \& Picornell, R. M. (2009). Yield and yield components of saffron under different cropping systems. Industrial Crops and Products, 30, 212-219. https://doi.org/10.1016/ j.indcrop.2009.03.011

El Takach, T., Chehabeddin, H., El Hajj, A., \& Isaa El khoury, M. (2017). Saffron production as extra income for women in Lebanese rural areas. $8^{\text {th }}$ International Agricultural Symposium, Bosnia and Herzegovina.

Golmohammadi, F. (2014). Saffron and Its Farming, Economic Importance, Export, Medicinal Characteristics and Various Uses in South Khorasan Province-East of Iran. International Journal of Farming and Allied Sciences.

Gresta, F., Lombardo, G. M., Siracusa, L., \& Ruberto, G. (2008). Saffron, an alternative crop for sustainable agricultural systems. A review. Agronomy for Sustainable Development, 28(1), 95-112. https://doi.org/ 10.1051/agro:2007030

Hussaini, A., Buullet, M., Ghani, Y., Kermani, N. A., Hassan, B., \& Muzaffar, M. (2010). Saffron (Crocus Sativus Kashmirianus) cultivation in Kashmir: Practices and problems. Functional Plant Science and Biotechnology, Global Science Books.

Jami-alahmadi, M., Behdani, M. A., \& Akbarpouret, A. (2010). Analysis of Agronomic Effective Factors on Yield of Saffron-based Agroecosystems in Southern Khorassan. Conference Paper in Acta Horticulturae. https://doi.org/10.17660/ActaHortic.2010.850.19

Kafi, M., Koocheki, A., \& Rashed, M. H. (2006). Saffron (Crocus sativus) production and processing. An Imprint of Edenbridge Ltd., British Isles, United State of America.

Koocheki, A., \& Seyyedi, S. M. (2016). Effects of Different Water Supply and Corm Planting Density on Crocin, Picrocrocin and Safranal, Nitrogen Uptake and Water Use Efficiency of Saffron Grown in Semi-Arid Region. Not Sci Biol, 8(3), 334-341. https://doi.org/10.15835/nsb839855

Kumar, R., \& Shamra, O. S. (2017). Pistil and corm yield of rainfed saffron (Crocus sativus L.) as influenced by land configuration and corm densities. The Bioscan, 12(2), 1075-1083

Kumar, R., Singh, M. K., \& Ahuja, P. S. (2012). Effect of planting depth and spacing on dry matter accumulation, size and yield of saffron (Crocus sativus L.) in North Western Hialayas. Progressive Horticulture, 44(1), 71-79. https://scialert.net/abstract/?doi=ajps.2008.747.751

Kumar, R., Singh, V., Devi, K., Shamra, M., Singh, M. K., \& Ahuja, P. S. (2009). Reviews International State of Art of Saffron (Crocus sativus L.) Agronomy: A Comprehensive Review. Food Reviews International.

McGimpsey, J. A., Douglas, M. H., \& Wallace, A. R. (1997). Evaluation of saffron (Crocus sativus L.) production in New Zealand. New Zealand Journal of Crop and Horticultural Science, 25(2), 159-168. https://doi.org/10.1080/01140671.1997.9514002

Mollafilabi, A., Koocheki, A., Moeinerad, H., \& Kooshki, L. (2013). Effect of Plant Density and Weight of Corm on Yield and Yield Components of Saffron (Crocus sativus L.) under Soil, Hydroponic and Plastic Tunnel Cultivation. Proc. IS on Medicinal and Aromatic Plants-SIPAM 2012.

Mousavi, S. Z., \& Bathaie, S. Z. (2011). Historical uses of saffron: Identifying potential new avenues for modern research. Avicenna Journal of Phytomedicine, 1(2), 57-66

Seyyedi, S. M., Ebrahimian, E., \& Rezaei-Chiyaneh, E. (2018). Saffron daughter corms formation, nitrogen and phosphorous uptake in response to low planting density, sampling rounds, vermicompost and mineral fertilizers. Commmunication in Soil Science and Plant Analysis, 49(5), 585-603. https://doi.org/10.1080/ 00103624.2018 .1432634

Yau, S. K., \& Nihmeah, M. (2004). Spacing effects on corm and flower production o Saffron (Crocus sativus). Lebanese Science Journal, 5(2).

\section{Copyrights}

Copyright for this article is retained by the author(s), with first publication rights granted to the journal.

This is an open-access article distributed under the terms and conditions of the Creative Commons Attribution license (http://creativecommons.org/licenses/by/4.0/). 